\title{
Research Article \\ Survey of Oxygen Delivery Practices in UK Paediatric Intensive Care Units
}

\author{
Sainath Raman, Samiran Ray, and Mark J. Peters \\ Respiratory, Critical Care and Anaesthesia Group, Infection, Immunity, Inflammation and Physiological Medicine Programme, \\ Institute of Child Health, University College London and Great Ormond Street Hospital, Great Ormond Street, \\ London WC1N 3JH, UK \\ Correspondence should be addressed to Sainath Raman; sainath.raman@ucl.ac.uk
}

Received 19 April 2016; Accepted 26 June 2016

Academic Editor: Robert Boots

Copyright (C) 2016 Sainath Raman et al. This is an open access article distributed under the Creative Commons Attribution License, which permits unrestricted use, distribution, and reproduction in any medium, provided the original work is properly cited.

Purpose. Administration of supplemental oxygen is common in paediatric intensive care. We explored the current practice of oxygen administration using a case vignette in paediatric intensive care units (PICU) in the united kingdom. Methods. We conducted an online survey of Paediatric Intensive Care Society members in the UK. The survey outlined a clinical scenario followed by questions on oxygenation targets for 5 common diagnoses seen in critically ill children. Results. Fifty-three paediatric intensive care unit members from 10 institutions completed the survey. In a child with moderate ventilatory requirements, 21 respondents (42\%) did not follow arterial partial pressure of oxygen $\left(\mathrm{PaO}_{2}\right)$ targets. In acute respiratory distress syndrome, cardiac arrest, and sepsis, there was a trend to aim for lower $\mathrm{PaO}_{2}$ as the fraction of inspired oxygen $\left(\mathrm{FiO}_{2}\right)$ increased. Conversely, in traumatic brain injury and pulmonary hypertension, respondents aimed for normal $\mathrm{PaO}_{2}$ even as the $\mathrm{FiO}_{2}$ increased. Conclusions. In this sample of clinicians $\mathrm{PaO}_{2}$ targets were not commonly used. Clinicians target lower $\mathrm{PaO}_{2}$ as $\mathrm{FiO}_{2}$ increases in acute respiratory distress syndrome, cardiac arrest, and sepsis whilst targeting normal range irrespective of $\mathrm{FiO}_{2}$ in traumatic brain injury and pulmonary hypertension.

\section{Introduction}

The administration of supplemental oxygen is common in the critically ill. The aim is to augment oxygen delivery to the tissues [1]. Hyperoxia can lead to production of reactive oxygen species and cell injury $[2,3]$. Conversely, hypoxia causes cell death. The "ideal" $\mathrm{PaO}_{2}$ target range is unclear. Consequently clinical practice varies.

Eastwood et al. reported that $77 \%$ of intensivists in Australia and New Zealand prescribed oxygen saturation targets. Clinicians working in regional centers were less concerned with oxygen toxicity [4]. De Graaff et al. explored the response of Dutch clinicians to arterial blood gas values $(\mathrm{ABG})$ in tertiary intensive care units. The $\mathrm{FiO}_{2}$ was reduced in only $25 \%$ of situations with a $\mathrm{PaO}_{2}>16 \mathrm{kPa}$ [5].

The etiology and evolution of paediatric critical illness are different to adults. Multiorgan failure (MOF) occurs early in children and they have better survival $[6,7]$. Nonetheless, the duration of mechanical ventilation and length of stay in the paediatric intensive care unit is increasing [8]. This survey aimed to describe prevalent paediatric intensive care practice, existence of weaning protocols, and if a clinical equipoise exists between liberal and restrictive oxygenation targets.

\section{Material and Methods}

All the members of the Paediatric Intensive Care Society (PICS), UK, were requested to complete an online survey. PICS consists of nursing, medical, and allied health professionals working in paediatric intensive care units. The practitioners from the neonatal intensive care units in UK were not approached, as their patient profile is significantly different.

The survey was designed by the authors and published using a survey website (https://opinio.ucl.ac.uk). Demographic data including age, ICU type, their seniority, and years of practice were sought. The study was discussed with the chair of Bloomsbury Research and Ethics Committee (London, UK). We were advised that a formal ethics review was not required. 
TABLE 1: Characteristics of respondents.

\begin{tabular}{lc}
\hline $\begin{array}{l}\text { Number of admissions/year to your intensive care } \\
\text { unit }\end{array}$ & Number (\%) \\
\hline$<500$ & $9(17.6)$ \\
$501-1000$ & $24(47)$ \\
$1001-1500$ & $13(25.5)$ \\
$>1500$ & $5(9.8)$ \\
No response & 2 \\
\hline Cardiosurgical center & $33(66)$ \\
\hline Neurosurgical center & $35(67)$ \\
\hline Grade of respondent & \\
\hline Consultant & $25(48)$ \\
Senior nurse & $10(19.2)$ \\
Senior fellow & $12(23)$ \\
Junior fellow & $5(9.6)$ \\
No response & 1 \\
\hline Number of years of practice in intensive care & $13(25.5)$ \\
\hline 2-5 years & $13(25.5)$ \\
$5-6$ years & $25(49)$ \\
$>10$ years & 2 \\
No response &
\end{tabular}

The survey outlined the following clinical scenario: a 1year-old patient with no premorbid conditions is ventilated with peak inspiratory pressure of $28 \mathrm{~cm} \mathrm{H}_{2} \mathrm{O}$, positive end expiratory pressure of $6 \mathrm{~cm} \mathrm{H} \mathrm{H}_{2} \mathrm{O}$, respiratory rate of 20 breaths per min, and $\mathrm{FiO}_{2}$ of 0.8 . His peripheral oxygen saturation (pulse oximetry), heart rate, blood pressure, and mean blood pressure are 94\%, 125 beats per min, $85 / 56 \mathrm{mmHg}$, and $66 \mathrm{mmHg}$, respectively. He has bilaterally equal and reactive pupils measuring $3 \mathrm{~mm}$. He is sedated on intravenous morphine and midazolam. He is not paralysed. Latest arterial blood gas values are as follows: $\mathrm{pH}$ : 7.32, $\mathrm{PCO}_{2}$ : $6.2 \mathrm{kPa}, \mathrm{PaO}_{2}$ : $10 \mathrm{kPa}, \mathrm{BE}$ : -ve 4 , and lactate: $1.5 \mathrm{mmol} / \mathrm{L}$. The PIM2 predicted risk of mortality is $8.8 \%$. He has been ventilated for 2 days.

With the same clinical history, clinicians were asked to decide on the oxygenation targets when the potential diagnosis is ARDS, CA, Sepsis, TBI, or PHTN.

A further question explored if weaning protocols were in place in their units. The need for a randomised control trial (RCT) with tight arterial oxygenation targets was explored.

\section{Results}

Only 30\% (53) of those whom were invited to participate in the online survey responded. The majority of respondents worked in moderate sized ICUs, with admission rates between 500 and 1000 patients per annum. The characteristics of the respondents are presented in Table 1.

The majority of units (96\%) had an alarm target on their oxygen saturation monitor. Thirty-eight respondents (73\%) worked in units that did not have an oxygen weaning protocol for mechanically ventilated patients. The units with admissions more than 1500 were less likely to have a weaning protocol compared to those between 500 and 1500 admissions.

For the given clinical scenario, 21 respondents (42\%) did not follow $\mathrm{PaO}_{2}$ targets. Of the rest, 21 clinicians (42\%) targeted $\mathrm{PaO}_{2}$ between 8.1 and $10 \mathrm{kPa}$. Only 8 (16\%) aimed for the normal range $(10.1-13 \mathrm{kPa})$.

In ARDS, CA, and sepsis, there was a tendency to aim for lower $\mathrm{PaO}_{2}(<10 \mathrm{kPa})$ as the $\mathrm{FiO}_{2}$ increased. This was noticeable when the $\mathrm{FiO}_{2}$ was more than 0.4 (45\%) which equates to a $\mathrm{PaO}_{2} / \mathrm{FiO}_{2}$ ratio of less than 200. Following TBI and in PHTN, there was a propensity to aim for normal $\mathrm{PaO}_{2}$ $(10.1-13 \mathrm{kPa})$ even as the $\mathrm{FiO}_{2}$ rose $\left(28-33 \%\right.$ when $\mathrm{FiO}_{2}>$ $0.4)$. In TBI, the proportion of respondents targeting a lower $\mathrm{PaO}_{2}$ increased when the $\mathrm{FiO}_{2}$ was more than 0.8 (8\%). A proportion of respondents targeted $\mathrm{PaO}_{2}$ ranges above normal (15\%). In PHTN, normal range remained the preferred range throughout the range of $\mathrm{FiO}_{2}$ (Figure 1).

The initial scenario was further extended as "no improvement after 24 hours of intensive care." The management strategy did not change in this setting.

Thirty-nine percent considered it ethical to conduct a RCT with tight arterial oxygenation target whilst 11\% did not. The remaining respondents were undecided.

\section{Discussion}

Our survey shows that, practice variation notwithstanding, there seems to be a general consensus to aim for lower $\mathrm{PaO}_{2}$ in the setting of ARDS, CA, and sepsis. The results are consistent with higher $\mathrm{PaO}_{2}$ targets being chosen in children following TBI and in PHTN. Only a small proportion of respondents felt a RCT with tight oxygenation target would be unethical.

Paediatric intensivists tolerate a low $\mathrm{SpO}_{2}$ target (88\%) with a low tidal volume strategy for ARDS [9]. Our findings concur. A recent point prevalence study reported that adult intensive care practitioners aim to prevent low oxygen saturation $\left(\mathrm{SpO}_{2}<90 \%\right)$ but fail to address high saturations [10]. This is in the face of mounting evidence of harm from hyperoxia [11]. Should we aim for a restrictive oxygenation target in critically ill patients? The "HOT or NOT" trial showed that separation between titrated oxygen target and standard target is possible in intensive care [12]. A recent multicenter study demonstrated no difference in 90-day mortality between mechanically ventilated patients randomised to a conservative (pulse oximetry: 88-92\%) and liberal oxygenation targets $(>96 \%)$ [13]. A larger randomised control trial is awaited.

The main limitation of this survey is the likely low response rate. At the time of the survey the membership of the society was not well defined. Responses were not sought beyond a single e-mail. The low number of respondents from junior staff perhaps suggests that considerable experience is needed to set distinct targets in these clinical scenarios. Despite this limitation, the results indicate that restrictive targets are aimed for in certain scenarios.

We had intended to analyse Cohen's kappa to look at interrater agreement. However, due to the small sample size a formal statistical analysis was not attempted. 


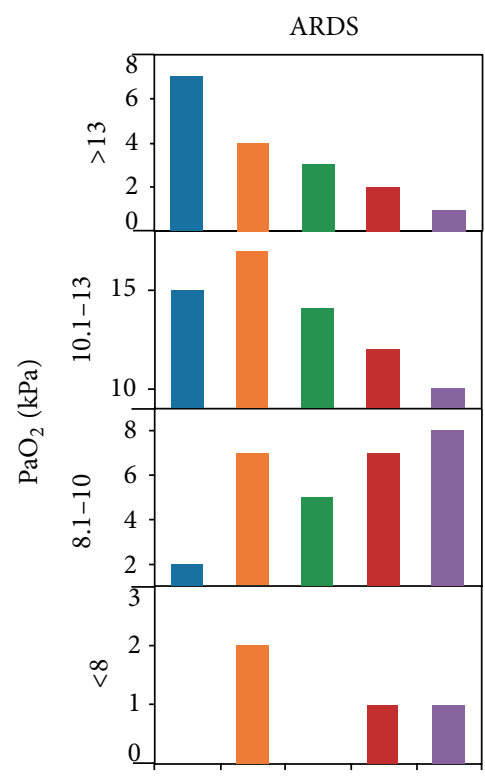

$\mathrm{FiO}_{2}$

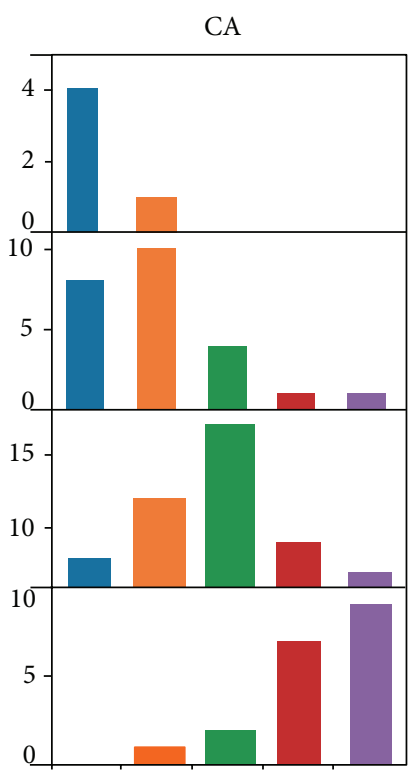

$\mathrm{FiO}_{2}$

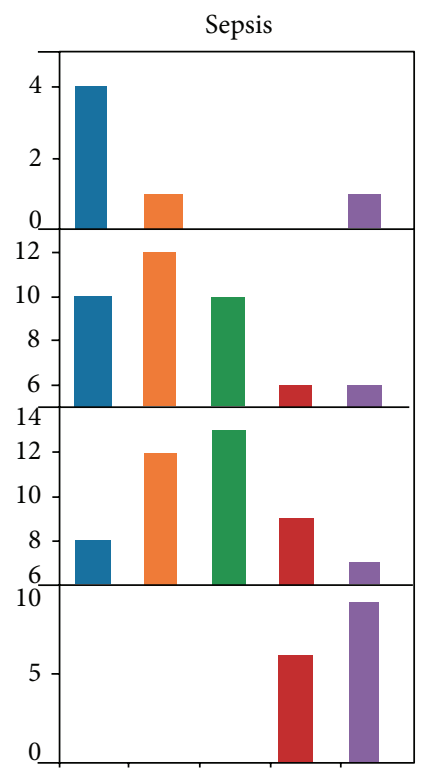

$\mathrm{FiO}_{2}$
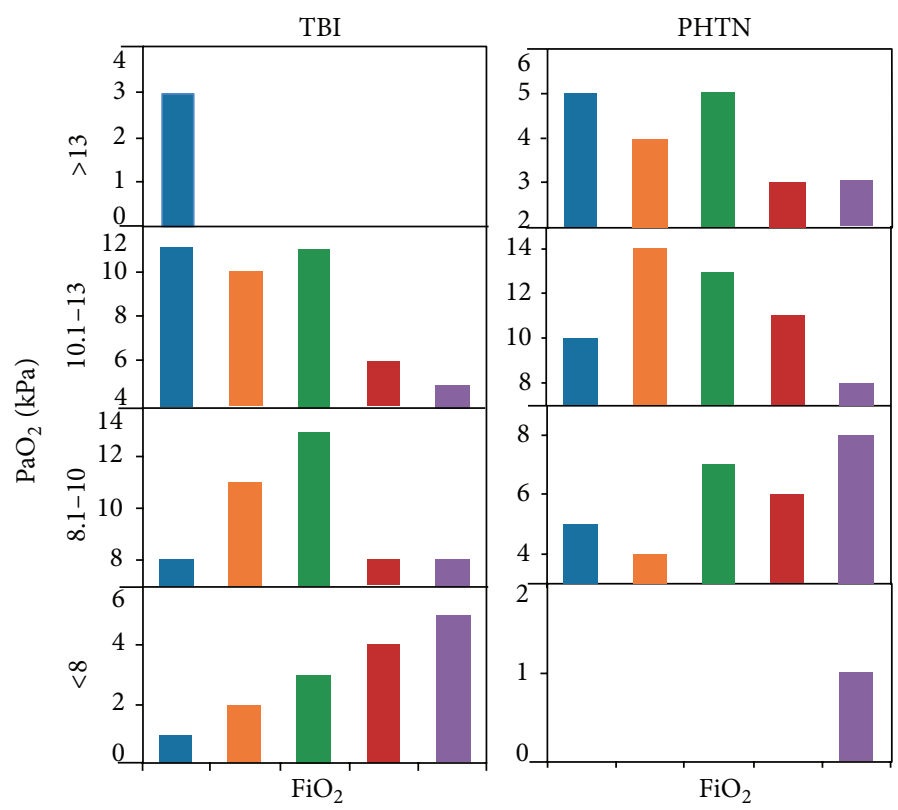

$\mathrm{FiO}_{2}$

0.21

$0.61-0.8$

$0.22-0.4$

$0.81-1$

$0.41-0.6$

FIgure 1: The profile of $\mathrm{PaO}_{2}$ ( $y$-axis) and $\mathrm{FiO}_{2}$ ( $x$-axis) targeted in 5 clinical scenarios in a child with moderate ventilatory requirements. The $\mathrm{PaO}_{2}$ ranges from $<8 \mathrm{kPa}$ in the bottom panel to $>13 \mathrm{kPa}$ in the top panel within each scenario. $\mathrm{FiO}_{2}$ ranges from 0.21 (blue) through to 0.81-1 (purple). The three scenarios in the upper section show a pattern of more restrictive $\mathrm{PaO}_{2}$ targets with increasing $\mathrm{FiO}_{2}$. The 2 scenarios in the lower section show that higher normal $\mathrm{PaO}_{2}$ ranges are targeted irrespective of increasing $\mathrm{FiO}_{2}$.

\section{Conclusions}

In this study variability and lack of consensus are consistent with an assumption of clinical equipoise. Supplemental oxygen administration practices and oxygenation target practices vary. A majority of respondents worked in units with no oxygen weaning protocol. A proportion of clinicians do not follow $\mathrm{PaO}_{2}$ targets. Clinicians aim for lower $\mathrm{PaO}_{2}$ thresholds in ARDS, CA, and sepsis whilst aiming for the normal range in TBI and PHTN. The lack of consensus and the large variability in practice demonstrate equipoise. This should be addressed with a feasibility trial comparing restrictive to 
standard oxygenation targets in critically ill children to lead up to a future RCT.

\section{Disclosure}

Dr. Raman is a holder of HCA fellowship.

\section{Competing Interests}

The authors declare that they have no competing interests.

\section{References}

[1] D. F. Treacher and R. M. Leach, "ABC of oxygen: oxygen transport-1. Basic principles," British Medical Journal, vol. 317, no. 7168, pp. 1302-1306, 1998.

[2] H. J. F. Helmerhorst, M. J. Schultz, P. H. J. van der Voort, E. de Jonge, and D. J. van Westerloo, "Bench-to-bedside review: the effects of hyperoxia during critical illness," Critical Care, vol. 19, article 284, 2015.

[3] S. Magder, "Reactive oxygen species: toxic molecules or spark of life?” Critical Care, vol. 10, no. 1, article 208, pp. 1-8, 2006.

[4] G. M. Eastwood, M. C. Reade, L. Peck, D. Jones, and R. Bellomo, "Intensivists' opinion and self-reported practice of oxygen therapy," Anaesthesia and Intensive Care, vol. 39, no. 1, pp. 122-126, 2011.

[5] A. E. De Graaff, D. A. Dongelmans, J. M. Binnekade, and E. De Jonge, "Clinicians' response to hyperoxia in ventilated patients in a Dutch ICU depends on the level of $\mathrm{FiO}_{2}$," Intensive Care Medicine, vol. 37, no. 1, pp. 46-51, 2011.

[6] J.-L. Vincent, A. D. Mendonça, F. Cantraine et al., "Use of the SOFA score to assess the incidence of organ dysfunction/failure in intensive care units: results of a multicenter, prospective study," Critical Care Medicine, vol. 26, no. 11, pp. 1793-1800, 1998.

[7] S. Leteurtre, A. Duhamel, B. Grandbastien et al., "Daily estimation of the severity of multiple organ dysfunction syndrome in critically ill children," Canadian Medical Association Journal, vol. 182, no. 11, pp. 1181-1187, 2010.

[8] Network PICA, PICANet Annual Report 2013, PICANet, 2013.

[9] M. Santschi, A. G. Randolph, P. C. Rimensberger, and P. Jouvet, "Mechanical ventilation strategies in children with acute lung injury: a survey on stated practice pattern," Pediatric Critical Care Medicine, vol. 14, no. 7, pp. e332-e337, 2013.

[10] P. J. Young, R. W. Beasley, G. Capellier, G. M. Eastwood, and S. A. R. Webb, "Oxygenation targets and monitoring in the critically ill: a point prevalence study of clinical practice in australia and New Zealand," Critical Care and Resuscitation, vol. 17, no. 3, pp. 202-207, 2015.

[11] E. Damiani, E. Adrario, M. Girardis et al., "Arterial hyperoxia and mortality in critically ill patients: a systematic review and meta-analysis," Critical Care, vol. 18, no. 1, article 711, 2014.

[12] P. Young, M. Bailey, R. Bellomo et al., "HyperOxic Therapy OR NormOxic Therapy after out-of-hospital cardiac arrest (HOT OR NOT): a randomised controlled feasibility trial," Resuscitation, vol. 85, no. 12, pp. 1686-1691, 2014.

[13] R. Panwar, M. Hardie, R. Bellomo et al., "Conservative versus liberal oxygenation targets for mechanically ventilated patients -a pilot multicenter randomized controlled trial," American Journal of Respiratory and Critical Care Medicine, vol. 193, no. 1, pp. 43-51, 2016. 


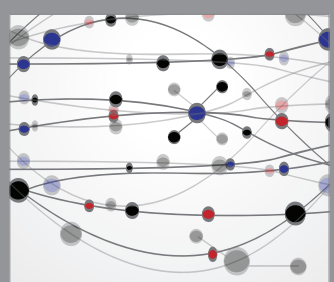

The Scientific World Journal
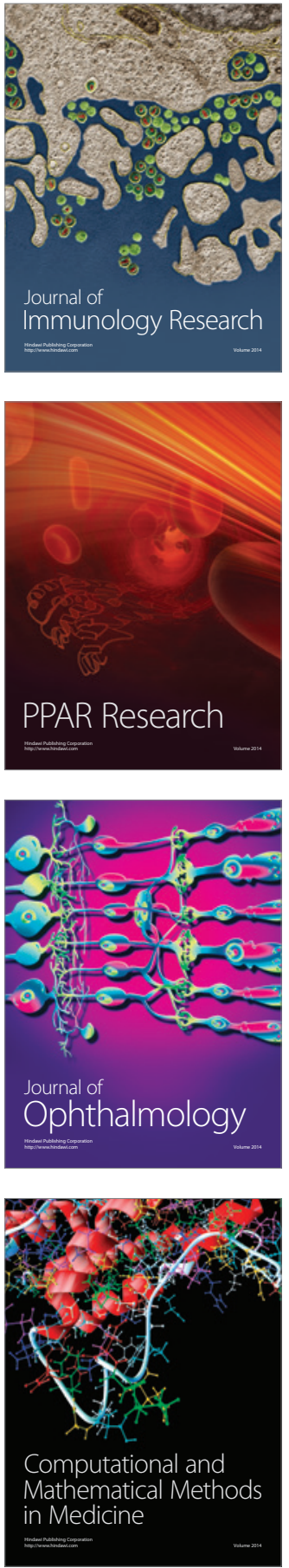

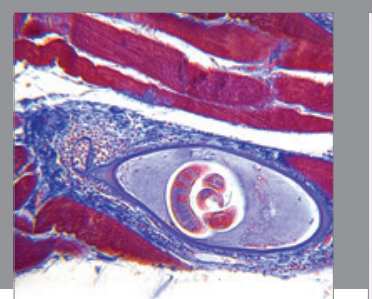

Gastroenterology Research and Practice

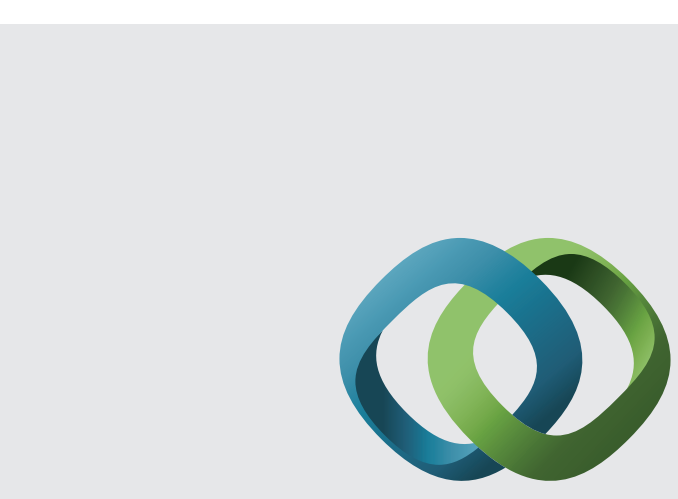

\section{Hindawi}

Submit your manuscripts at

http://www.hindawi.com
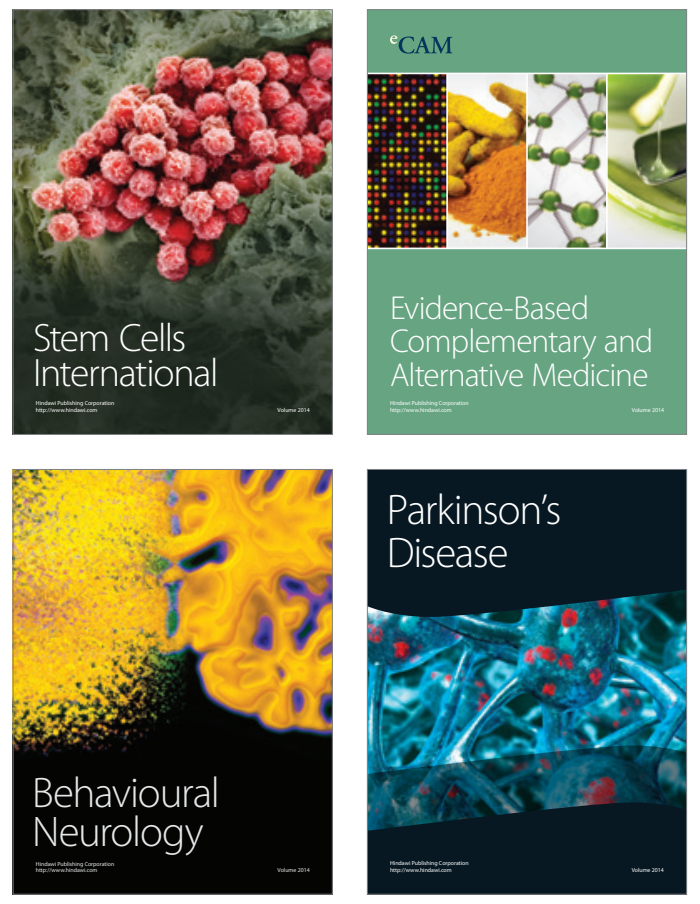
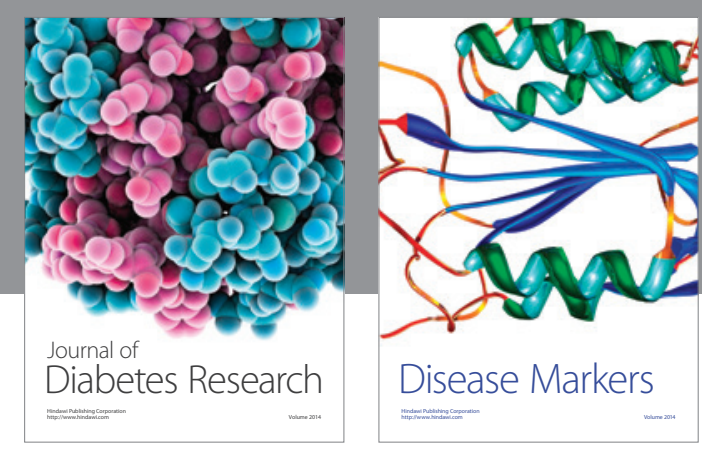

Disease Markers
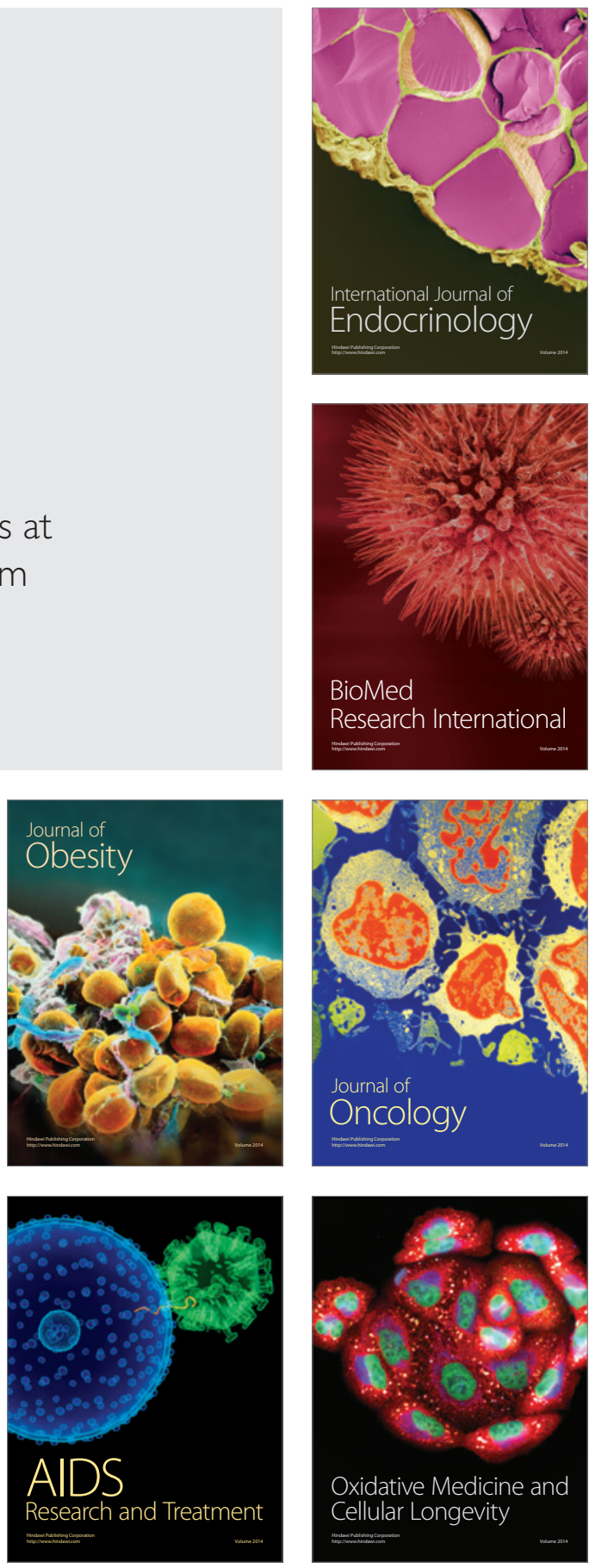